\title{
Water retention curve and hydraulic conductivity function of highly compressible materials
}

Serge-Étienne Parent ${ }^{1}$, Alexandre Cabral ${ }^{2 *}$, and Jorge G. Zornberg ${ }^{3}$

Paper accepted with minor corrections by the

Canadian Geotechnical Journal

1 Postdoctoral researcher, Dept. Civil Eng., Univ. de Sherbrooke, Quebec, Canada

2 Professor, Dept. Civil Eng., Univ. de Sherbrooke, Sherbrooke, Quebec, Canada

${ }^{3}$ Associate Professor, Dept Civil Eng., University of Texas at Austin

* Author to whom all correspondence should be sent:

Département de génie civil, Faculté de génie, Université de Sherbrooke.

2500, boul. de 1'Université, Sherbrooke, Québec, Canada J1K 2R1

Tel.: 819-821-7906; Fax: 819-821-7974

Alexandre.Cabral@,Usherbrooke.ca

Parent, S.E., Cabral, A.R. and Zornberg, J.G.\# (2007). Water retention curve and hydraulic conduc-tivity function of highly compressible materials. Canadian Geotechnical Journal, 44: 1200-1214. 
Water retention curve and hydraulic conductivity function of highly compressible materials

Serge-Étienne Parent, Alexandre Cabral, and Jorge G. Zornberg

Abstract: A model capable of describing the suction-induced consolidation curve (void ratio function) and water retention curve (WRC) of highly compressible materials (HCM) is developed, validated and finally applied to describe the WRC of deinking by-products (DBP). DBP are a highly compressible by-product of paper recycling used in geoenvironmental applications. Validation is conducted by modelling the WRC and the void ratio function for a well-documented silty sand from Saskatchewan, Canada. The WRC and void ratio function were used to predict its hydraulic conductivity function ( $k$-function). The water content, suction and volumetric deformation data of DBP are obtained using an experimental technique that allows determination of the WRCs of HCMs that is suitable for prediction of the DBP $k$-function. The results show that volumetric water contents are underestimated if volume changes are not accounted for, leading to inaccuracies in the WRCs, thus inaccurate predicted $k$-functions. It is shown that the newly developed model is better suited for HCMs than currently available models, in particular for HCMs that continue to undergo significant volume changes when the applied suction exceeds the air entry value.

Keywords: Water retention curve, Hydraulic conductivity function, Compressible materials, Deinking by-products 
Courbe de rétention d'eau et fonction de conductivité hydraulique des matériaux hautement compressibles

Serge-Étienne Parent, Alexandre Cabral, et Jorge G. Zornberg

Résumé : Un modèle conçu pour décrire la courbe de consolidation induite par la tension capillaire (fonction d'indice des vides) ainsi que la courbe de rétention d'eau (CRE) des matériaux hautement compressibles (MHC) est développé, validé, puis appliqué pour décrire la CRE des sous-produits de désencrages (SPD). Les SPD sont un sous-produit hautement compressible issus du procédé de recyclage du papier utilisé pour des applications géoenvironnementales. La validation du modèle est effectuée en modélisant la CRE et la fonction d'indice des vides d'un sable limoneux documenté, provenant de la Saskatchewan, au Canada. La CRE et la fonction d'indice des vides ont ensuite été utilisées pour prédire sa fonction de conductivité hydraulique $(\mathrm{FCH})$. Les données de teneur en eau, de tension capillaire et de déformation volumique des SPD sont obtenues grâce à une procédure expérimentale permettant de déterminer la CRE des MHC. Les résultats montrent que la teneur en eau volumique est sous-estimée si les changements de volume de l'échantillon ne sont pas pris en compte, menant à des imprécisions dans la CRE, et, ainsi, dans la FCH prédite. Il est démontré que le nouveau modèle est plus approprié pour les MHC que les modèles présentement disponibles, en particulier pour les MHC qui continuent à subir des changements de volumes significatifs pour des valeurs de succions plus élevées que la valeur d'entrée d'air.

Mots clés : Courbe de rétention d'eau, fonction de conductivité hydraulique, matériaux compressibles, sous-produits de désencrage 


\section{INTRODUCTION}

Highly compressible materials (HCM) such as highly plastic clays and organic soils are being increasingly used in geoenvironmental and agricultural applications (Nemati et al. 2002; Paquet et al. 1993). In particular, deinking by-products (DBP), a material produced from early stages of paper recycling processes, have been successfully used as cover material in both landfills (Kamon et al. 2002; Kraus et al. 1997; Moo-Young 1996) and mining applications (Cabral et al. 1999) as well as a soil structural enhancement material in agricultural applications (Nemati et al. 2000).

The water retention curve (WRC), also known as the soil-water characteristic curve, constitutes a basic relationship between moisture and suction used for prediction of the mechanical and hydraulic behaviour of unsaturated porous materials. The experimental characterization of WRCs using traditional equipment, such as pressure plates (Smith and Mullins 2001), and their representation using available models (e.g. Brooks and Corey 1964; Fredlund and Xing 1994; van Genuchten 1980) may not be adequate for HCMs because these materials undergo significant volume changes when their pore structure is subjected to suction even for suction values higher than the air-entry value. Huang et al. (1998) proposed a model to fit WRC data from HCMs. However, Huang et al. (1998)'s model does not allow representation of some features that are relevant for HCMs, such as non linear variation of the void ratio for suctions lower than the air-entry value, partial desaturation that occurs in the vicinity of the airentry value, and variation of the void ratio for suctions higher than the air-entry value.

The hydraulic conductivity function, also known as $k$-function, is the relationship between hydraulic conductivity function and suction. Because of experimental difficulties involved in its direct determination, conventional practice has been to indirectly estimate the $k$ - 
function using experimental WRC data and Mualem (1976) analytical relationship (Fredlund 2002; Fredlund et al. 1994; Huang et al. 1998; Leong and Rahardjo 1997b). Huang et al. (1998) proposed a minor modification to the Fredlund et al. (1994) $k$-function model, which was inspired by the Child and Collis-George (1950) model, to account for volume changes. The suitability of the $k$-function depends not only on the adopted $k$-function model, but also on the adequacy of the experimental WRC results and model used to derive the $k$-function. However, the development to date of methods suitable to determine the WRC and $k$-functions for HCMs has been, at least, limited.

This paper presents the details of an experimental technique used to determine the WRC of HCMs (updated from Cabral et al. 2004). The testing procedure is based on the axistranslation technique and allows for simultaneous and continuous determination of the volumetric water content and void ratio of soil samples during desaturation. A model is also developed to describe the suction-induced shrinkage, the WRC and the $k$-function of HCMs. The proposed model is based on a model originally proposed by Fredlund and Xing (1994) and is initially validated using experimental data reported by Huang et al. (1998), who performed a series of tests on a compressible silty sand from Saskatchewan, Canada. The experimental results of representative tests performed to determine the WRC of DBP are subsequently presented and evaluated. Finally, the $k$-functions for DBP, determined using the proposed WRC model, are obtained and compared to results obtained using a method that does not consider volumetric changes.

\section{BACKGROUND}

\section{Water Retention Curve}


The relationship between water content and suction in a porous material provides the basis for understanding and predicting of the mechanical and hydraulic response of unsaturated porous materials used in geotechnical and soil science applications. Theoretical background useful for the prediction of the engineering behaviour of unsaturated soils using the WRC is presented by Barbour (1998). Leong and Rahardjo (1997a) summarize currently available models used to represent the WRCs.

Figure 1 shows a schematic representation of a set of WRCs for highly compressible specimens of the same material prepared to initial void ratios $e_{0_{-} i}, e_{0_{-} i i}$ and $e_{0_{-} i i i}$. The initial saturated moisture content $\theta_{s}$ for the three specimens is different, but the various WRCs presented as $\theta$ versus $\psi$ define a single desaturation branch (solid thick line in) for suction levels exceeding the air-entry value ( $\psi_{a e v}$ ) of each specimen (Toll 1988). The $\psi_{a e v}$ is the suction value where significant water losses are observed in the largest pores of the specimen. As discussed later, the $\psi_{a e v}$ depends on the initial void ratio and on the nature of void ratio changes with increasing suction. In the case of HCMs, the $\psi_{a e v}$ should be determined on a degree of saturation $(S)$ versus suction $(\psi)$ relationship (also shown in), rather than on the volumetric water content versus suction curve, because the volumetric water content of a compressible specimen can start to decrease while the material remains saturated. That is, since water is expelled from the pores due to suction-induced changes in void ratio, the volumetric water content in compressible materials before reaching the $\psi_{a e v}$ while the degree of saturation remains constant (Fig. 1).

The shape of the WRC is mainly influenced by the soil pore size distribution and by the compressibility of the material (Smith and Mullins 2001). In turn, the soil pore size distribution and compressibility are affected by the initial water content, soil structure, mineralogy and stress history (Lapierre et al. 1990; Simms and Yanful 2002; Vanapalli et al. 1999). Volumetric 
changes induced during desaturation (shrinkage) can influence significantly the shape of the WRC. Specifically, the volumetric changes affect the calculated volumetric water content $(\theta)$ or degree of saturation $(S)$. Accordingly, accounting for suction-induced volumetric changes plays a significant role on the accuracy of the WRC (Price and Schlotzhauer 1999). Cabral et al. (2004) describes a testing apparatus, based on the axis translation technique, that allows measurement of volumetric changes continuously during determination of the WRC in HCMs.

An extensive body of literature exists regarding experimental techniques for determination of WRCs (Smith and Mullins 2001). Indirect methods based on grain size distribution (i.e. a measure of the pore size distribution) are also widely used to obtain WRCs (Arya and Paris 1981; Aubertin et al. 2003; Zhuang et al. 2001). However, these methods are not suitable for fibrous materials such as DBPs and do not account for suction-induced reduction in pore size. Also, it should be noted that most models used to fit WRC data have been developed explicitly assuming that the material would not be subjected to significant volume changes (Brooks and Corey 1964; Fredlund and Xing 1994; van Genuchten 1980). In particular, the WRC model proposed by Fredlund and Xing (1994) was developed based on the assumption that the shape of the WRC depends on the pore size distribution of the porous material. The Fredlund and Xing (1994) model is expressed as follows:

$$
\begin{aligned}
& \text { [1a] } \theta=\frac{C(\psi) \theta_{s}}{\ln \left[2.71828+\left(\psi / a_{F X}\right)^{n_{F X}}\right]^{m_{F X}}} \quad \text { or } \quad S=\frac{C(\psi)}{\ln \left[2.71828+\left(\psi / a_{F X}\right)^{n_{F X}}\right]^{n_{F X}}} \\
& \text { [1b] } C(\psi)=1-\frac{\ln (1+\psi / C r)}{\ln \left(1+10^{6} / C r\right)}
\end{aligned}
$$

where $\theta$ is the volumetric water content, $\theta_{s}$ is the saturated volumetric water content, $S$ is the degree of saturation, $\psi$ is the matric suction, $a_{F X}$ is a parameter proportional to the air-entry value, $n_{F X}$ is a parameter related to the desaturation branch of the slope of the WRC, $m_{F X}$ is a 
parameter related to the residual portion (tail end) of the $\mathrm{WRC}, C(\psi)$ is a correcting function used to force the WRC model to converge to a null water content at a suction of $10^{6} \mathrm{kPa}$ and $\mathrm{Cr}$ is a suction value corresponding to the residual water content (Fredlund and Xing 1994).

Huang et al. (1998) developed a WRC model that accounts for volumetric changes. Based on experimental data reported in the literature, Huang et al. (1998) assumed that the logarithm of the air-entry value $\left(\psi_{a e v}\right)$ is linearly proportional to the void ratio, as follows.

[2] $\quad \psi_{\text {aev }}=\psi_{\text {aev } \_} e^{1} 10^{\varepsilon_{\psi}\left(e-e^{\prime}\right)}$

where $e$ is the void ratio, $e^{\prime}$ is a reference void ratio, $\psi_{\text {aev } \_} e^{\prime}$ is the air-entry value at the reference void ratio $e^{\prime}, \varepsilon_{\psi}$ is the slope of the $\log \psi_{a e v}$ vs. $e$ curve, and $\psi_{a e v}$ is the air-entry value at the void ratio $e$. The air-entry value of a tested specimen can be defined using the tangent method proposed by Fredlund and Xing (1994) or the Brooks \& Corey (1964) model optimized using least squares. Kawai et al. (2000) present an exponential regression quite similar to eq. [2].

Huang et al. (1998) describe the WRC of a deformable unsaturated porous media using their adaptation of the Brooks and Corey (1964) model, as follows:

[3a] $S_{e}=1$ for $\psi \leq \psi_{\text {aev } \_e^{\prime}} 10^{\varepsilon\left(e-e^{\prime}\right)}$

[3b] $S_{e}=\left[\frac{\psi_{\text {aev_e } e^{\prime}} 10^{\varepsilon\left(e-e^{\prime}\right)}}{\psi}\right]^{\lambda}$ for $\psi>\psi_{\text {aev_e }} 10^{\varepsilon\left(e-e^{\prime}\right)}$

where $S_{e}$ is the normalized degree of saturation $\left[S_{e}=\left(S-S_{r}\right) /\left(1-S_{r}\right)\right], S_{r}$ is the residual degree of saturation, $\lambda$ is the pore size distribution index for a void ratio $e$ and represents the slope of the desaturation branch. The parameter $\lambda$ typically ranges from 0.1 for clays to 0.6 for sands (van Genuchten et al. 1991). 
Shrinkage reduces the slope of the desaturation branch of the WRC. Based on experimental evidence, Huang et al. (1998) assumed that the relationship between $\lambda$ and void ratio for HCMs can be represented by:

[4] $\lambda=\lambda_{e^{\prime}}+d\left(e-e^{\prime}\right)$

where $d$ is an experimental parameter and $\lambda_{e}$, is the pore-size distribution index for the reference void ratio $e^{\prime}$. It should be noted that the Huang et al. (1998) model does not account for suctioninduced volumetric changes, nor for slight decreases in the degree of saturation that is generally observed on the WRC before the AEV is reached.

\section{The hydraulic conductivity function}

The hydraulic conductivity function ( $k$-function) of unsaturated soils can be determined directly in the laboratory (McCartney and Zornberg 2005) or in the field. It can also be determined indirectly using empirical, macroscopic or statistical models. Leong and Rahardjo (1997b) summarize available models used to indirectly determine the $k$-function from WRCs.

Parent et al. (2004) proposed a methodology to determine the $k$-function of HCMs using the saturated hydraulic conductivity $\left(k_{s a t}\right)$ and the $\psi_{a e v}$ obtained from tests performed on samples with different initial void ratios. Huang et al. (1998) proposed to account for the effect of $e$ on $k_{\text {sat }}$ and on the resulting $k$-function, as follows:

$$
\begin{aligned}
& k(e(\psi))=k_{\text {sat }}(e(\psi)) k_{r}(\psi) \\
& k_{\text {sat }}(e(\psi))=k_{\text {sat_e }} 10^{b\left(e(\psi)-e^{\prime}\right)}
\end{aligned}
$$

where $k(e(\psi))$ is the hydraulic conductivity, $k_{\text {sat }}(e(\psi))$ is the saturated hydraulic conductivity at void ratio $e(\psi), k_{r}(\psi)$ is the relative $k$-function described using a model such as that from Fredlund et al. (1994), $k_{\text {sat_e }}$, is the saturated hydraulic conductivity at the reference void ratio $e^{\text {, }}$ 
and $b$ is the slope of the $\log \left(k_{s a t}\right)$ vs. $e$ relationship. The relative $k$-function, $k_{r}$, and the void ratio, $e$, can be expressed as a function of either $\theta$ or $\psi$. Since the void ratio of HCMs is a function of suction (Khalili et al. 2004), it is convenient to use a $k$-function model described in terms of suction.

In order to determine $k_{r}$, Fredlund et al. (1994) proposed the statistical model of eq. [6] based on the model developed by Child and Collis-George (1950):

$$
k_{r}(\psi)=\int_{\ln (\psi)}^{\ln \left(10^{6}\right)} \frac{\theta\left(2.71828^{y}\right)-\theta(\psi)}{2.71828^{y}} \theta^{\prime}\left(2.71828^{y}\right) d y / \int_{0}^{\ln \left(10^{6}\right)} \frac{\theta\left(2.71828^{y}\right)-\theta_{s}}{2.71828^{y}} \theta^{\prime}\left(2.71828^{y}\right) d y
$$

where $\theta^{\prime}$ is the derivative of the WRC model and $y$ is a dummy variable of integration representing suction.

It should be noted that the Childs and Collis-George (1950) $k$-function, used as basis for eqs. [5] and [6], assumes that the soil structure is incompressible (Fredlund and Rahardjo 1993). In fact, the function on the numerator of eq. [6] involves an integral for suction values ranging from $\psi$ to the maximum suction value $\left(10^{6} \mathrm{kPa}\right)$, while the denominator involves an integral for the entire suction range (from 0 to $10^{6} \mathrm{kPa}$ ). However, the expression in the denominator is sensible to the initial void ratio. This is illustrated in Fig. 1, which shows a schematic representation of three water retention tests performed using different initial void ratios. For example, it is expected that at suction $\psi_{x}$ samples $i i$ and $i i$ will reach the same void ratio, the same volumetric water content and, consequently, the same hydraulic conductivity. However, integration of the WRCs for samples $i i$ and iii will lead to a greater value in the denominator of eq. [6] for sample $i i$ (areas $\mathrm{A}+\mathrm{B}+\mathrm{C}$ ) than for sample iii (areas $\mathrm{B}+\mathrm{C}$ ), leading to different $k$ function. Improvements in the prediction of the $k$-functions for HCMs are beyond the scope of this paper and deserve further attention from researchers. 


\section{MATERIALS AND METHODS}

\section{Deinking by-products}

Deinking by-products (DBP) are fibrous, highly compressible residues of paper recycling processing. The inorganic components of DBP include calcite, meta-kaolinite and rutile, while the organic components include cellulose, hemicellulose and lignin (Panarotto et al. 1999). The maximum dry unit weight obtained following Standard Proctor procedure ranges from 5.0 to 5.6 $\mathrm{kN} / \mathrm{m}^{3}$ and optimum gravimetric water content ranges from 60 to $90 \%$.

Figure 2 presents the consolidation curves of two DBP specimens. The results show that DBP present a relatively short primary consolidation phase (barely invisible in Fig. 2) and a significantly larger secondary consolidation (creep) phase, a behaviour resembling that of highly organic materials such as peat. Figure 2 also shows the time-dependent nature of the settlements in three sectors of the Clinton mine cover, Quebec, Canada, illustrating that field behaviour is consistent with the laboratory response. Specifically, the field results in Fig. 2 reveal that the short primary consolidation phase involve only the initial two months, followed by a long creep phase (Bédard 2005).

Hydraulic conductivity tests were performed in oedometers at the end of each consolidation step using in the laboratory specimens. Figure 3 shows the saturated hydraulic conductivity obtained for a series of tests performed using samples collected from different sites and prepared at an average initial gravimetric water content of approximately 138\% (approximately $60 \%$ above the optimum water content). As expected, the saturated hydraulic conductivity increases with increasing void ratio. The slope of the $k_{s a t}$ versus $e$ relationship (the parameter $b$ in eq. [5b]) equals 0.95 .

\section{Testing equipment}


Figure 4 shows a schematic view of the testing apparatus used in this study to obtain the water retention curve (WRC) of DBP. The system consists of a 115.4-mm high, 158.5-mm diameter Plexiglas cell, a pressure regulator used to control air pressure applied on the top of the specimen and on the burette CELL, and three valves that allow control of air pressure, water inflow and water outflow. As the air pressure applied on the top of the specimen is increased, water is expelled from the sample and collected in burette OUT. Volume changes in the specimen during pressure increases result in an equivalent water volume entering the cell via the burette CELL. The continued measurement of volume changes allows calculation of the volumetric water content at each suction level. Additional details on the equipment characteristics and testing procedures are provided by Cabral et al. (2004).

Cabral et al. (2004) used a porous stone of negligible air-entry value (0-bar porous stone). However, as suction increased beyond the $\psi_{a e v}$ of DBP, air broke into the specimen, draining the porous stone and compromising the results. In the present study, testing was performed using porous stones with air-entry values of 1 and 5 bars $(1 \mathrm{bar}=101.3 \mathrm{kPa})$. The use of porous stones of higher air-entry values allows determination of WRC data up to suction values of $100 \mathrm{kPa}$ and $500 \mathrm{kPa}$, respectively. The time needed to reach equilibrium in the burettes OUT and CELL after each pressure increment was carefully evaluated. Consistent readings could be obtained after 24 hours where using the 0 bar porous stone and after 2 to 5 days where using the 1-bar and 5-bar porous stones, depending on the level of applied pressure.

\section{Specimen preparation}

Specimen preparation involves initial autoclaving of the DBP material to prevent biological activity during testing. Planchet (2001) observed that the use of microbiocide affects 
the pore structure of DBP by altering its fibres. Consequently, no microbiocide was added to the DBP specimens tested in this study.

Preliminary tests with DBP showed that the sample preparation procedure that led to the best reproducibility of results involved compacting three $10 \mathrm{~mm}$-thick layers by tamping the material directly into the cell. For that purpose, a mould and small mortar were designed and constructed. The thickness of the layers was controlled using a specially designed piston. Cabral et al. (2004) provide additional details on the procedure used for sample preparation and compaction. The characteristics of the samples of DBP prepared for this study, modified cell tests (MCT 1 to 4$)$ are presented in Table 1.

\section{Testing procedure and calibration}

Following specimen preparation, the apparatus is assembled and the consolidation phase is initiated. Consolidation was conducted during 120 minutes under a cell confining pressure of 5 $\mathrm{kPa}$. The valve allowing air into the sample remained closed during this initial phase. Pressure was then raised to $20 \mathrm{kPa}$ for a second consolidation phase that was conducted during 24 hours. A pressure of $20 \mathrm{kPa}$ corresponds approximately to the overburden pressure applied by the protection cover layers to a barrier layer of DBP.

The first data point of the WRC is obtained at the end of the consolidation phase under 20 $\mathrm{kPa}$, which occurs when the water levels in the burettes CELL and OUT reach equilibrium. Readings were initialized at this point, and air pressure increments of $2.5 \mathrm{kPa}$ (irregular increments for MCT4) were applied to the specimen until the suction corresponding to the $\psi_{\text {aev }}$ is reached and can be clearly identified on the $\psi$ vs. $\theta$ plot. Pressure increments of $10 \mathrm{kPa}$ are then applied at suction levels higher than the $\psi_{a e v}$ (irregular increments for MCT4). 
The volume of water entering the cell (from burette CELL) corresponds to volume changes in the specimen and is recorded during each pressure increment. The water volume reaching the burette OUT is also recorded as it corresponds to the volume of water lost from the specimen. The system was calibrated to account for the expansion of the cell and the lines. The calibration procedure is described by Cabral et al. (2004). After considering the appropriate corrections to the recorded values, the water content and degree of saturation of the specimen can be determined for each level of applied air pressure. Since the axis translation technique is employed in this approach, the air pressure corresponds to the suction within the specimen. The volumetric water content was considered stabilized when two consecutive measurements, taken $24 \mathrm{~h}$ apart, showed a difference of less than $0.25 \%$ in water content (less than $0.5 \%$ for MCT4).

The tests were terminated when suction reached the air-entry value of the porous stone. The cell was then disassembled and the final dimensions and weight of the specimen were recorded.

\section{PROPOSED WRC CURVE MODEL FOR HCMs}

For the purpose of this study, it is assumed that the volumetric moisture content of highly compressible materials (HCM) prepared under different initial void ratios converge towards the same value as suction increases (Fig. 1). Accordingly, it can be expected that, beyond a certain suction value, the parameters governing the shape of the WRC reach the same values. The water retention curve (WRC) model proposed herein, which is based on Fredlund and Xing (1994), is able to describe multiple WRC test results for the same HCM with different initial void ratios using a single set of parameters. Specifically, the Fredlund and Xing (1994) model was adapted by formulating the four parameters $\left(a_{F X}, n_{F X}, m_{F X}\right.$ and $\left.\theta_{s}\right)$ as a function of the initial void ratio. In 
this section, a void ratio function model, a WRC model and a hydraulic conductivity function $(k$ function) model are presented.

While hysteresis may play an important role on the hydraulic behaviour of HCM materials (Price and Schlotzhauer 1999), the hysteretic response of DBP is beyond the scope of the present study. Instead, only the desaturation phase is evaluated.

\section{Void ratio function}

Figure 5 presents the void ratio versus suction as defined from four representative modified cell tests conducted using DBP (tests MCT1 to MCT4). A normal stress of $20 \mathrm{kPa}$ was applied along the entire test in each test. A series of suction increments were imposed. The results from an oedometer test on DBP are also shown in Fig. 5. At least for the range of effective stresses applied in these tests, the consolidation curve shows a pattern that is consistent with that of the suction induced behaviour.

The model proposed by Huang et al. (1998) assumed that changes in void ratio occur only for values of matric suction below the AEV $\left(\psi_{\text {aev }}\right)$. However, the results shown in Fig. 5 for tests MCT1 to MCT4 indicate that such assumption is not adequate for HCMs such as deinking byproducts (DBP). Indeed, the void ratio continues to decrease significantly for suction values well beyond the $\psi_{a e v}$. An exponential model, adapted from a model reported by Ratkowski (1989), is proposed to describe the relationship between void ratio and suction, as follows:

[7] $e=e_{c}+\left(e_{0}-e_{c}\right)\left(1+c_{1} e_{0} \psi\right)^{c_{2}}$

where $e$ is the void ratio at suction $\psi, e_{0}$ is the void ratio in the beginning of the suction test, and $c_{1}, c_{2}$ and $e_{c}$ are fitting parameters. The parameter $e_{c}$ is the void ratio at which the $e$ vs. $\psi$ curves, obtained from suction tests conducted using specimens prepared at different initial void ratios converge. The numerical value of parameters $e_{c}, c_{1}$ and $c_{2}$ for DBP is independent of 
the initial void ratio $e_{0}$, and were obtained by fitting the experimental data from tests MCT1 to MCT4 using least squares. The values obtained for these parameters are presented as an insert in Fig. 5.

\section{Water retention model}

Generally, porous materials do not have a single pore size and the largest pores desaturate prior to the smaller ones. As a consequence, a gradual - often slight - desaturation takes place for suction values below $\psi_{a e v}$. This is the case for peat, as shown by Weiss et al. (1998), Schlotzhauer and Price (1999) and Brandyk et al. (2002), and for DBP, as shown by Cabral et al. (2004). Therefore, the two-phase behaviour of Huang et al. (1998)'s model (eq. [3]) may lead to a model bias. The Fredlund and Xing (1994) model (eq. [1]) was adapted in this study to account for volume changes.

Based on experimental evidence reported in the literature, Huang et al. (1998) assumed that $\log \psi_{a e v}$ is proportional to the void ratio (eq. [2]). Figure 6 shows the relationship between $\log \psi_{\text {aev }}$ and $e$ as obtained from suction tests performed as part of this study using DBP (tests MCT1 to MCT4) and additional tests reported by Cabral et al. (2004). In the cases where a 0-bar porous stone was employed (tests reported by Cabral et al. 2004), the $\psi_{a e v}$ was considered to correspond to the suction value when air broke through the sample. In the cases where 1-bar or 5-bar porous stones were employed (tests MCT1 to MCT4), the $\psi_{a e v}$ was considered to correspond to the suction value where departure from full saturation was observed on the $S$ versus $\psi$ curve. The actual value was defined by the inflection point as determined using the procedure proposed by Fredlund and Xing (1994). The relationship between log $\psi_{a e v}$ and $e$ is approximately linear and can be described using eq. [2]. Indeed, in the present case, rather than analyzing the casual sigmoïdal curve describing the WRC, it can be useful to analyse the actual 
behaviour of the material as it undergoes desaturation. A curve has an inflexion range where one can define an air entry value. On the other hand, a material with a void ratio $e_{i}$ desaturates as if it would reach the air-entry value at $\psi_{a e v i}$. However, its void ratio decreases to $e_{i i}$ on the next suction increment. At this moment, the material with void ratio $e_{i i}$ desaturates as if it would reach the air-entry value at $\psi_{\text {aevii. }}$. For a suction value higher than the actual air-entry value, the material with void ratio $e_{i i i}$ as if it would reach the air-entry value at $\psi_{a e v i i i}$. And so on.

Figure 6 could be drawn for any porous material: not compressible, compressible or highly compressible. Figure 6 is not used as a proof of material compressibility, but as an index on how the AEV depends on void ratio. Indeed, Fig. 5 shows that the void ratio diminishes with increasing suction and Fig. 6 shows that a lower void ratio gives a higher air-entry value. Hence, the air-entry value can be a function of suction. The parameter $a_{F X}$ defines the lateral position of the WRC and is linearly proportional to $\psi_{a e v}$ (Fredlund et al. 2002). As in the case of $\psi_{a e v}$, the variation of $a_{F X}$ with void ratio, at least for $\mathrm{HCM}$, was assumed to follow the following relationship:

$$
a_{F X}=a_{F X_{-} e^{e}} 10^{\varepsilon_{a}\left(e-e^{\prime}\right)}
$$

where $a_{F X_{-}} e$ is the value of $a_{F X}$ at a reference void ratio $e^{\prime}$ and $\varepsilon_{a}$ is the slope of the $\log a_{F X}$ vs. $e$ curve.

The variations of parameters $n_{F X}$ and $m_{F X}$ from eq. [1] are based on the same rational than the one presented for the variation of $a_{F X}$. However, in a similar manner to the case of the parameter $\lambda$, which is assumed to vary linearly with $e$ (eq. [4]), the parameters $n_{F X}$ and $m_{F X}$ are assumed to vary linearly with $e$, as follows:

[9] $n_{F X}=n_{F X_{-} e^{\prime}}+\varepsilon_{n}\left(e-e^{\prime}\right)$ 


$$
m_{F X}=m_{F X_{-} e^{\prime}}+\varepsilon_{m}\left(e-e^{\prime}\right)
$$

where $n_{F X_{-} e^{\prime}}$ and $m_{F X_{-} e^{\prime}}$ are the parameters $n_{F X}$ and $m_{F X}$ at the reference void ratio $e^{\prime}$, and $\varepsilon_{n}$ and $\varepsilon_{m}$ are fitting parameters obtained by least square minimization of WRC data. Given that the slope of the WRC is null when $n_{F X}=1\left(e^{\prime}=e_{c}\right)$, the value of $n_{F X \_}$, approaches unity for HCMs.

In order to reduce the number of parameters, i.e. instead of using different values of $e^{\prime}$ for each equation and for each test, $e_{c}$ could be adopted for $e^{\prime}$. The WRC model proposed in this study is finally obtained by inserting eq. [7] into eqs. [8] to [10], and inserting eqs. [8] to [10] into eq. [1], while considering $e^{\prime}=e_{c}$ :

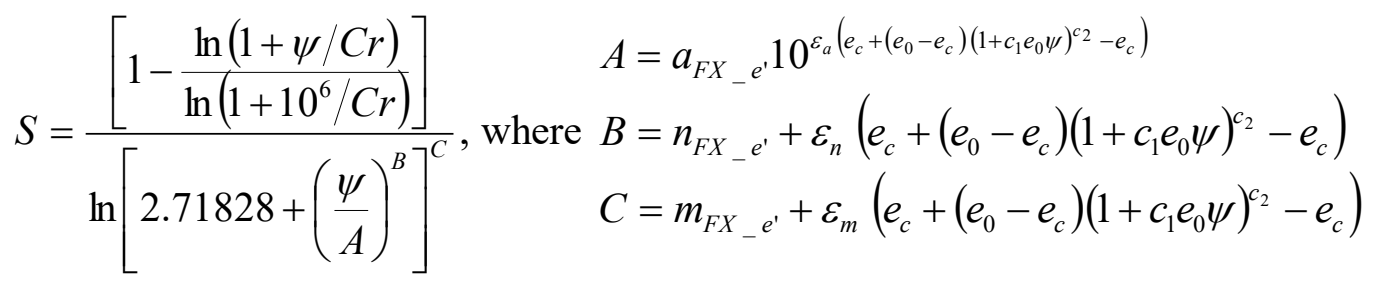

The WRC model proposed in this study is supported by a theoretical framework and is expected to be suitable to most HCMs. Validation of this model is presented next using results reported by Huang (1994) for a compressible silty sand and is followed by the use of the model on DBP using results obtained as part of this study.

\section{Validation of the proposed model}

In order to validate the proposed model (eq. [11]), the procedure for obtaining the WRC and predicting the $k$-function was applied to experimental data reported by Huang et al. (1998) involving a series of tests on a compressible silty sand from Saskatchewan, Canada. The experimental data were collected using pressure-plate cells. Since volumetric changes were not recorded during testing, the variation of void ratio with suction was obtained from the results of 
flexible-wall permeability tests performed by Huang et al. (1998) using specimens with similar initial void ratio.

Use of the proposed model implies that the void ratio of the silty sand converges toward a single value at high suction values. This assumption is not observed on the results of Huang et al. (1998). Indeed, their silty sand did not shrink for suctions greater than the air-entry value. In this paper, this silty sand was used due to lack of data in the literature concerning HCM. The WRC and $k$-function models developed here cannot be applied for "normally" compressible materials because the void ratio stops to vary for suctions greater than the AEV. As a consequence, the validation made here is limited and its completion would require further testing using HCM. The proposed model was applied to fit the results of suction test data for specimens PPCT13, PPCT16 and PPCT22, taken from Huang et al. (1998), by maximising $\mathrm{R}^{2}$. The parameter $a_{F X}$ was obtained from the $\log \psi_{a e v}$ versus $e$ relationship presented on Figure 19 in by Huang et al. (1998), where the $\psi_{a e v}$ was determined on the $S$ versus $\psi$ curve. Figure 7 shows the results of Huang et al. (1998) fitted using the proposed model, which fits rather well the experimental results using a single set of parameters. The three curves merge into a single desaturation curve for suction values beyond approximately $700 \mathrm{kPa}$.

Figure 8 presents the results of three flexible-wall unsaturated hydraulic conductivity tests (FWPT2, FWPT3 and FWPT6) on the Saskatchewan silty sand (Huang et al. 1998). These tests where selected because their initial void ratios are similar to those of tests PPCT13, PPCT22 and PPCT16, respectively. The $k$-function of the silty sand was estimated using eqs. [5] and [6] using the WRC parameters that corresponds to the proposed WRC model. The parameters for eq. [5b] are those reported by Huang et al. (1998). Since the derivative of the proposed WRC model ( $\theta^{\prime}$ in eq. [6]) is complex to determine, the symbolic computation 
program Maxima was used for its determination. The subsequent integration was performed using a Lobatto quadrature in a Matlab environment (TheMathWorks 2004).

Unlike the WRC predicted curves, which converges into a single desaturation branch, it can be observed that the $k$-functions are reasonably independent from each other. This is due to nature of eq. [6] as well as the assumption that the soil structure is incompressible. The results in Fig. 8 show a good agreement between model prediction and the experimental data for FWPT6. However, the agreement is not as good for tests FWPT2 and FWPT3. Test FWPT6 underwent little volumetric changes, which was not the case with FWPT2 and FWPT3. Equation [6] could be adapted to account for volume changes using expressions such as those used to account for volume changes in the WRC model proposed in this paper. However, mainly because of the lack of available experimental results, the development of a $k$-function model that considers shrinkage is beyond the scope of this paper. The next section includes the use of the proposed model to the results of suction tests conducted using DBP.

\section{USE OF THE PROPOSED WRC MODEL TO DEINKING BY-PRODUCTS}

\section{Water retention curve of deinking by-products}

Figure 9a presents the experimental data from suction tests conducted on deinking byproducts (DBP) to obtain the WRC (tests MCT1 to MCT4). The tests were conducted using the experimental procedure developed as part of this study. The initial void ratio and other characterristics of the specimens are indicated in Table 1. The degree of saturation data points presented in Fig. 9a were obtained considering volume changes in the data reduction process. That is, not only the changing volume of water but also the changing volume of pores was considered during computation of $S$. The proposed WRC model was subsequently employed to fit the four sets of experimental data. The parameter $\varepsilon_{a}$ was obtained using least square optimisation of the data 
representing the $\psi_{a e v}$ versus $e$ (Fig. 5). As shown in Fig. 9a, good agreement can be observed between the experimental results and the model predictions. As can observed, a single set of parameters is required to describe the WRC of the proposed model (see inserts in Fig. 9a), with the exception of $e_{0}$.

Fig. $9 \mathrm{~b}$ presents the experimental data from the same suction tests presented in Fig. 9a. However, the degree of saturation data points were obtained ignoring the volume changes in the data reduction process. The results in Fig. 9b, as compared to those in Fig. 9a, clearly show that volumetric water contents are underestimated if volume changes are not considered, particularly at high suction levels. Overall, the degree of saturation is significantly higher when accounting for volume changes. For example, for test MTC1, consideration of volume changes at a suction of approximately $20 \mathrm{kPa}$ leads to a degree of saturation 11\% higher (absolute difference) than that obtained when volume changes are neglected. At a suction of $90 \mathrm{kPa}$, the difference in degree of saturation is as high as 32\% (absolute difference). The Fredlund and Xing (1994) model was used to fit experimental data of Fig. 9b. Since the volume of the samples is considered constant, it is not possible to describe the WRC using a single set of parameters. Rather, the relevant parameters were obtained independently for each test. Their values, averages and the standard deviations are shown in Table 2.

\section{Hydraulic conductivity functions for deinking by-products}

Figure 10a shows the hydraulic conductivity function ( $k$-function) for tests MCT1 to MCT4. The curves were obtained using the measured $k_{\text {sat }}$ and their respective WRC that as determined using the proposed model (eq. [11]). The value of $k_{\text {sat }}$ was determined based on the initial void ratio $\left(e_{0}\right)$ of each test (Table 1$)$ using eq. [5b]. 
As shown in Fig. 10a, the different $k$-functions obtained using eqs. [5] and [6] tend to a single branch for suction values exceeding approximately $200 \mathrm{kPa}$, whereas convergence for the void ratio (Fig. 5) and for the degree of saturation (Fig. 9a) occurs in the vicinity of $10000 \mathrm{kPa}$.

Overall, for suction values exceeding approximately $1000 \mathrm{kPa}$, the average pore sizes of samples are quite similar. This is also the case for volumetric water content of the various specimens. Consequently, the hydraulic conductivity values at this level of suction are expected to be the same. However, eq. [6], which is used to determine the $k_{r}$ (thus the $k$-function), does not take into account the decrease in void ratio due to applied suction; as a consequence, one should not expect the $k$-functions to converge to a single branch, because the denominator would be influenced by the initial void ratio. In the case of DBP, the low standard deviation for $e_{i}$ explains the observed convergence, whereas for the silty sand the initial void ratio values are rather different and convergence is not observed (Fig. 8).

Figure 10b presents the $k$-functions for DBP defined by neglecting volume changes using the parameters for the WRC as determined using the model proposed by Fredlund and Xing (1994) (eq. [1]), whose parameters are presented in Table 2. At high suctions, convergence is not observed (Fig. 10b). In fact, four distinct curves are obtained for the four specimens. The differences in the values of the Fredlund and Xing (1994) parameters $a_{F X}, n_{F X}, m_{F X}$ and $C_{r}$ lead to differences in hydraulic conductivity of over one order of magnitude for a wide range of suction values.

CONCLUSIONS

A model was proposed to describe the water retention curve (WRC) of highly compressible materials (HCM). The input parameters needed for the model were obtained directly from suction tests performed using an experimental procedure that allows determination 
of the WRCs of materials that undergo significant volume changes during application of suction, i.e. HCMs. Monitoring of volume changes in the specimen during suction application allows continued update of the volumetric water contents.

The proposed model was validated using experimental data from tests reported for a compressible silty sand from Saskatchewan, Canada. Hydraulic conductivity functions ( $k$ functions) obtained based on the proposed WRC model shows poor agreement with hydraulic conductivity values obtained experimentally for this silty sand, due to the $k$-function model that was developed for incompressible structure.

The proposed model was used to represent the experimental results of suction tests conducted using deinking by-products (DBP), a highly compressible industrial by-product that can be used as alternative material in geoenvironmental applications. The proposed model was found to accurately fit the experimental WRC data. Volumetric water contents are significantly underestimated if volumetric changes are not accounted for in the data reduction process for determination of the WRC.

The void ratios of the DBP specimens tested were found to converge to a single curve as the suction level increases. Consequently, their $k$-functions are also expected to superimpose at comparatively high suctions. The results obtained in this study indicate that the $k$-functions defined using WRC models that account for volume changes converges to a single branch for comparatively high suctions, despite the fact that the $k$-function model was developed for incompressible structure. On the other hand, unrealistically different hydraulic conductivity branches were obtained at high suctions if volumetric changes are not accounted for.

Questions can be raised about the unicity of parameters $e_{c}, c_{1}$ and $c_{2}$ (eq. [7]; Fig. 5). A way to improve the model would be to obtain a void ratio at, for example, zero water content 
(1 $000000 \mathrm{kPa}$ ) for different samples. The void ratio of different specimens would converge to this single value of void ratio $\left(e_{c}\right)$. However, this convergence value would necessarily depend on the structure of the samples. If they are the same (it is difficult to obtain it for DBP samples), the convergence void ratio would be the same. An eventual difference in structure may induce some differences in the final void ratio. Nonetheless, it is important to note that the importance of the actual convergence value (or the "unique" value) is rather limited for the purposes of the model. Indeed, the value of $e_{c}$ does not affect the predictability of the model in terms of obtaining the WRC and k-fct, particularly for low suction range. For the higher suction range, it may have a more significant effect.

\section{ACKNOWLEDGEMENTS}

Funding for this study was provided by Industries Cascades Inc., Perkins Papers Ltd. and NSERC (Canada) under the University-Industry Partnership grant number CRD 192179 and by NSCRC under the Second Author's Discovery Grant. Support received by the last author from the National Science Foundation (US) is also greatly appreciated. The authors also acknowledge help provided by Jean-Guy Lemelin and Éric Drouin in the design of the cell and the measuring system and with the experimental testing.

\section{REFERENCES}

Arya, L.M., and Paris, J., F. 1981. A physicoempirical model to predict the soil moisture characteristic from particle-size distribution and bulk density data. Soil Science Society of America Journal, 45: 1023-1030.

Aubertin, M., Mbonimpa, M., Bussiere, B.R., and Chapuis, R. 2003. A model to predict the water retention curve from basic geotechnical properties. Canadian Geotechnical Journal, 40(6): 1104-1122. 
Audet, C., Lefebvre, G., Cabral, A.R., and Burnotte, F. 2002. State of development in the valorization of deinking by-products as an alternative to fine grained soils. In TAPPI 2002. Montreal. April 6-10, 2002. TAPPI.

Barbour, S.L. 1998. Nineteenth Canadian Geotechnical Colloquium: The soil-water characteristic curve: a historical perspective. Canadian Geotechnical Journal, 35(5): 873894.

Bédard, D. 2005. Effet du fluage à long terme des sous-produits de désencrage dû à la perte de masse et son effet sur la compression et la conductivité hydraulique. M.Sc.A. Thesis Civil Eng., Université de Sherbrooke.

Brandyk, T., Szatylowicz, J., Oleszczuk, R., and Gnatowski, T. 2002. Water-related physical attributes of organic soils. In Organic Soils and Peat Materials for Sustainable Agriculture. CRC Press. pp. 33-66.

Brooks, R.H., and Corey, A.T. 1964. Hydraulic properties of porous media. Hydrology paper no. 3, Colorado State University, Fort Collins, Colorado.

Burnotte, F., Lefebvre, G., Cabral, A., Audet, C., and Veilleux, A. 2000. Use of deinking residues for the final cover of a MSW landfill. In 53rd Canadian Geotechnical Conference. Montreal. October 15-18, 2000, Vol.1, pp. 585-591.

Cabral, A.R., Planchet, L., F.A., M., and Lefebvre, G. 2004. Determination of the Soil Water Characteristic Curve of Highly Compressible Materials: Case Study of Pulp and Paper By-Product. Geotechnical Testing Journal, 27(2): 154-162.

Cabral, A.R., Lefebvre, G., Burnotte, F., Panarotto, C.T., and Pastore, E. 1999. Use of pulp and paper residues as an alternative cover material to landfill and to acid generating tailings. 
In $2^{\circ}$ Seminario de Meio Ambiente em Industrias de Processo. Sao Paulo, Brazil. June 29-30, 1999, pp. 56-70.

Childs, E.C., and Collis-George, G.N. 1950. The permeability of porous materials. In Proceedings of the Royal Society of London, Series A. London, U.K., pp. 392-405.

Fredlund, D.G. 2002. Use of soil-water characteristic curve in the implementation of unsaturated soil mechanics. In Proceedings of the third International Conference on Unsaturated Soils. Recife, Brazil. March 20-23.

Fredlund, D.G., and Rahardjo, H. 1993. Soil mechanics for unsaturated soils, N.Y., Wiley,.

Fredlund, D.G., and Xing, A.Q. 1994. Equations for the Soil-Water Characteristic Curve. Canadian Geotechnical Journal, 31(4): 521-532.

Fredlund, D.G., Xing, A.Q., and Huang, S.Y. 1994. Predicting the Permeability Function for Unsaturated Soils Using the Soil-Water Characteristic Curve. Canadian Geotechnical Journal, 31(4): 533-546.

Fredlund, M.D., Wilson, G.W., and Fredlund, D.G. 2002. Use of the grain-size distribution for estimation of the soil-water characteristic curve. Canadian Geotechnical Journal, 39: 1103-1117.

Huang, S. 1994. Evaluation and laboratory mesurment of the coefficient of permeability in deformable unsaturated soilsThesis Department of civil engineering, University of Saskatchewan.

Huang, S.Y., Barbour, S.L., and Fredlund, D.G. 1998. Development and verification of a coefficient of permeability function for a deformable unsaturated soil. Canadian Geotechnical Journal, 35(3): 411-425. 
Kamon, M., Inazumi, S., Rajasekaran, G., and Katsumi, T. 2002. Evaluation of waste sludge compatibility for landfill cover application. Soils \& Foundations, 42(4): 13-27.

Kawai, K., Karube, D., and Kato, S. 2000. The Model of Water Retention Curve Considering Effects of Void Ratio. In Unsaturated Soils for Asia. Edited by H. Rahardjo, D.G. Toll, and E.C. Leong. Balkema, Rotterdam, pp. 329-334.

Khalili, N., Geiser, F., and Blight, G.E. 2004. Effective stress in unsaturated soils: Review with new evidence. International journal of Geomechanics, 4(2): 115-126.

Kraus, J.F., Benson, C.H., Van Maltby, C., and Wang, X. 1997. Laboratory and field hydraulic conductivity of three compacted paper mill sludges. Journal of Geotechnical and Geoenvironmental Engineering, 123(7): 654-662.

Lapierre, C., Leroueil, S., and Locat, J. 1990. Mercury Intrusion and Permeability of Louiseville clay. Canadian Geotechnical Journal, 27: 761-773.

Leong, E.C., and Rahardjo, H. 1997a. Review of Soil-Water Characteristic Curve Equations. Journal of Geotechnical \& Geoenvironmental Engineering, 123(12): 1106-1117.

Leong, E.C., and Rahardjo, H. 1997b. Permeability Functions for Unsaturated Soils. Journal of Geotechnical \& Geoenvironmental Engineering, 123(12): 1118-1126.

McCartney, J.S., and Zornberg, J.G. 2005. The Centrifuge Permeameter for Unsaturated Soils. In Experus 2005. Edited by A. Tarantino, E. Romero, and Y.J. Cui. Trento, Italy. 27-29 June.

Moo-Young, H.K., Jr., Zimmie, Thomas F. 1996. Effects of freezing and thawing on the hydraulic conductivity of paper mill sludges used as landfill covers. Canadian Geotechnical Journal, pp. 783-792. 
Mualem, Y. 1976. A new model for predicting the hydraulic conductivity of unsaturated porous media. Water Resources Research, 12: 513-522.

Nemati, M.R., Caron, J., and Gallichand, J. 2000. Using paper de-inking sludge to maintain soil structural form: Field measurements. Soil Science Society of America Journal, 64(1): 275-285.

Nemati, M.R., Caron, J., Banton, O., and Tardif, P. 2002. Determining air entry value in peat substrates. Soil Science Society of America Journal, 66(2): 367-373.

Panarotto, C.T., Robart, G., Cabral, A., Chartier, R., Burnotte, F., and Lefebvre, G. 1999. Using deinking residues in cover systems. In 7th Int. Waste Mgmt and Landfill Symposium SARDINIA 99. 4 - 8 octobre, S. Margherita di Pula, Italy, Vol.III, pp. 357-364.

Paquet, J.M., Caron, J., and Banton, O. 1993. Insitu Determination of the Water Desorption Characteristics of Peat Substrates. Canadian Journal of Soil Science, 73(3): 329-339.

Parent, S.-É., Cabral, A., Dell' Avanzi, E., and Zornberg, J.G. 2004. Determination of the Hydraulic Conductivity Function of a Highly Compressible Material Based on Tests with Saturated Samples Geotechnical Testing Journal, 27(6): 1-5.

Planchet, L. 2001. Utilisation des résidus de désencrage comme barrière capillaire et évapotranspirative (ET) pour les parcs à résidus miniers producteurs de DMA. M.Sc.A. Thesis Département de génie civil, Université de Sherbrooke.

Price, J.S., and Schlotzhauer, S.M. 1999. Importance of shrinkage and compression in determining water storage changes in peat: the case of a mined peatland. Hydrological Processes, 13(16): 2591-2601.

Ratkowski, D.A. 1989. Handbook of nonlinear regression models. Marcel Dekker. 
Schlotzhauer, S.M., and Price, J.S. 1999. Soil water flow dynamics in a managed cutover peat field, Quebec: Field and laboratory investigations. Water Resources Research, 35(12): 3675-3683.

Simms, P.H., and Yanful, E.K. 2002. Predicting soil-water characteristic curves of compacted plastic soils from measured pore-size distributions. Geotechnique, 52(4): 269-278.

Smith, K.A., and Mullins, C.E. 2001. Soil and environmental analysis : physical methods. Marcel Dekker, New York.

TheMathWorks 2004. MATLAB, Natick, Massachusetts, USA, pp. Technical computing language and interactive environment for algorithm development, data visualization, data analysis, and numeric computation.

Toll, D.G. 1988. The behaviour of unsaturated compacted naturally occurring gravelThesis Imperial College of Science, Medicine and Technology, University of London.

van Genuchten, M.T. 1980. A closed-form equation for predicting the hydraulic conductivity of unsaturated soils. Soil Science Society of America Journal, 44: 892-898.

van Genuchten, M.T., Leij, F.J., and Yates, S.R. 1991. The RETC code for quantifying the hydraulic functions of unsaturated soils, Report EPA/600/2-91/065, U.S. Department of Agriculture, Agriculture Research Service.

Vanapalli, S.K., Fredlund, D.G., and Pufahl, D.E. 1999. The influence of soil structure and stress history on the soil-water characteristics of a compacted till. Geotechnique, 49(2): 143159.

Weiss, R., Alm, J., Laiho, R., and Laine, J. 1998. Modeling Moisture Retention in Peat Soils. Soil Science Society of America Journal, 62(2): 305-313. 
Zhuang, J., Jin, Y., and Miyazaki, T. 2001. Estimating water retention characteristic from soil particle-size distribution using a non-similar media concept. Soil Science, 166(5): 308321. 


\section{List of Tables}

Table 1. Characteristics of the specimens tested in this study

Table 2. Parameters model for deinking by-product samples without consideration of volume change (Fredlund and Xing, 1994) 


\section{List of Figures}

Fig. 1. Schematic representation of WRCs for a material prepared at different initial void ratios

Fig. 2. Typical consolidation behaviour of deinking residues from laboratory testing and from field monitoring of 3 sites (adapted from Burnotte et al. (2000) and Audet et al. (2002)).

Fig. 3. Void ratio as a function of saturated hydraulic conductivity for deinking residues

Fig. 4. Schematic view of the testing apparatus used to obtain the WRC of DBP

Fig. 5. Suction-induced volumetric changes in DBP

Fig. 6. Air entry value as a function of void ratio for representative tests on DBP

Fig. 7. Proposed WRC model used to represent desaturation of a silty sand. Note: experimental data from Huang (1994)

Fig. 8. Hydraulic conductivity function for silty sand reported by Huang et al. (1998)

Fig. 9. Water retention curves for DBP: (a) considering (b) ignoring volumetric changes of shrinkage

Fig. 10. Hydraulic conductivity functions for DBP defined from models: (a) considering volumetric changes and (b) neglecting volumetric changes 
Table 1. Characteristics of the specimens tested in this study

\begin{tabular}{lcccc}
\hline & MCT1 & MCT2 & MCT3 & MCT4 \\
\hline Initial gravimetric water content (\%) & 196,9 & 153,6 & 210,3 & 188,5 \\
Unit weight $\left(\mathrm{kN} / \mathrm{m}^{3}\right)$ & 11,76 & 11,58 & 11,25 & 11,72 \\
Degree of saturation (\%) & 99,4 & 93,3 & 99,9 & 99,1 \\
Specific gravity (Gs) & 1,99 & 1,99 & 1,99 & 1,99 \\
Initial void ratio (after consolidation) & 3,89 & 3,28 & 3,67 & 2,70 \\
Porous stone used for the test & $1-$ bar & 1 -bar & $1-$ bar & 5 -bar \\
\hline Note: test results correspond to conditions in the mold before test assembly
\end{tabular}

Table 2. Parameters model for deinking by-product samples without consideration of volume change (Fredlund and Xing, 1994)

\begin{tabular}{|c|c|c|c|c|c|c|}
\hline & MCT1 & MCT2 & MCT3 & MCT4 & Average & Standard deviation \\
\hline$a_{F X}$ & 19,9 & 60,3 & 19,0 & 51,9 & 37,8 & 21,4 \\
\hline$n_{F X}$ & 1,81 & 1,14 & 1,83 & 1,50 & 1,57 & 0,32 \\
\hline$m_{F X}$ & 0,570 & 1,615 & 0,742 & 0,857 & 0,946 & 0,461 \\
\hline$C_{r}$ & 3000 & 3000 & 3000 & 3000 & 3000 & 0 \\
\hline$R^{2}$ & 0,998 & 0,999 & 0,999 & 0,998 & & \\
\hline
\end{tabular}




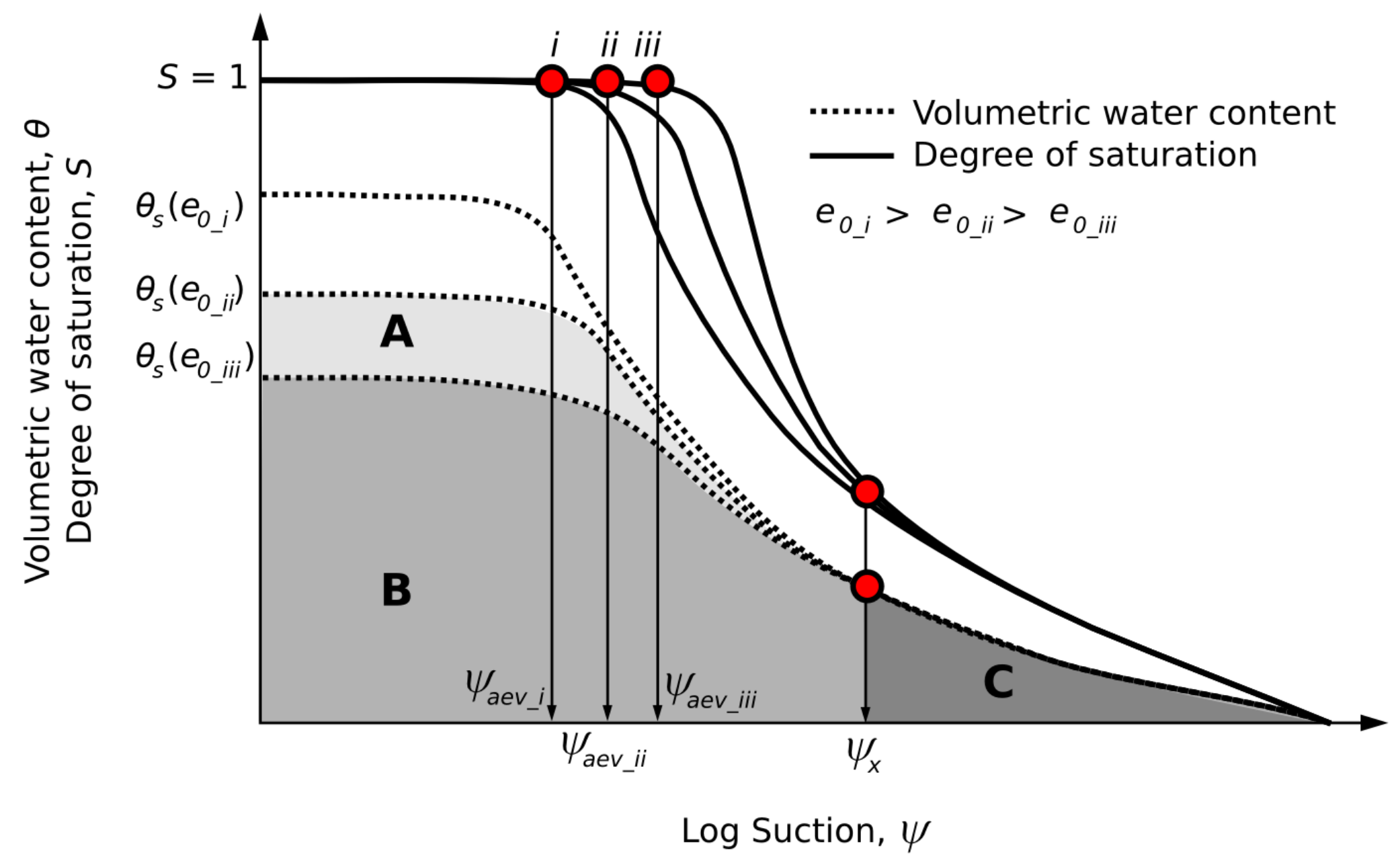

Fig. 1. Schematic representation of WRCs for a material prepared at different initial void ratios 


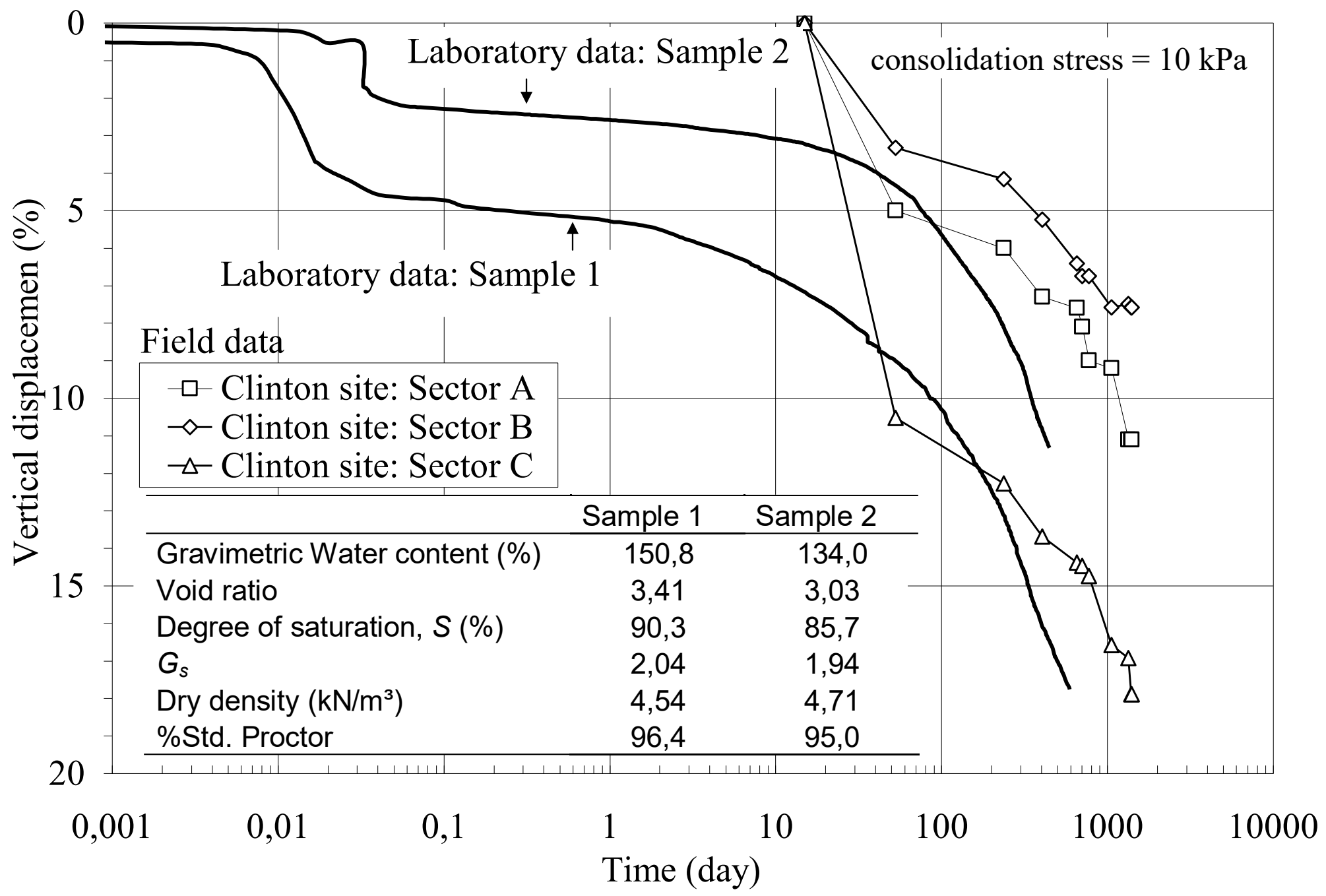

Fig. 2. Typical consolidation behaviour of deinking residues from laboratory testing and from field monitoring of 3 sites (adapted from Burnotte et al. (2000) and Audet et al. (2002)). 


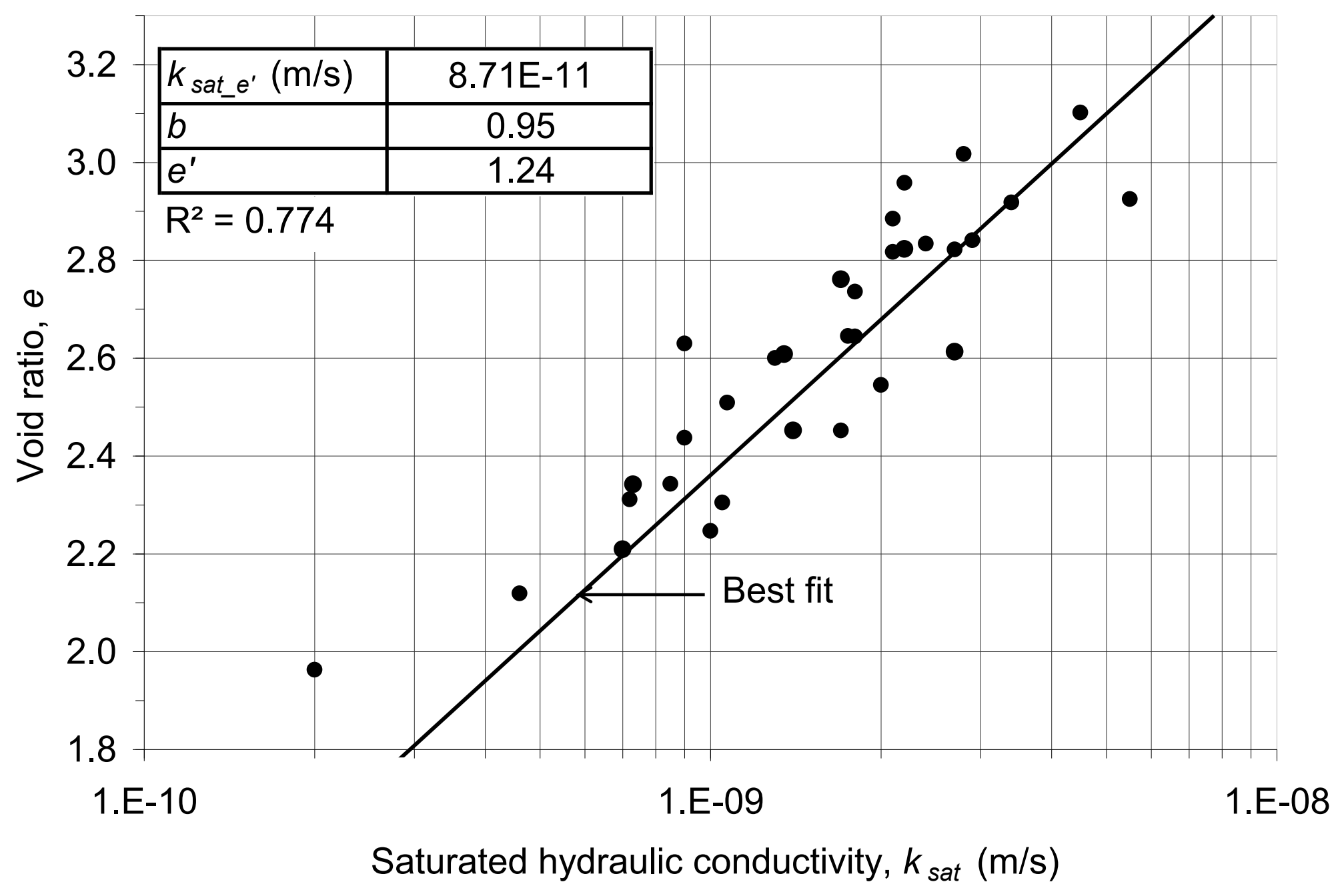

Fig. 3. Void ratio as a function of saturated hydraulic conductivity for deinking residues 


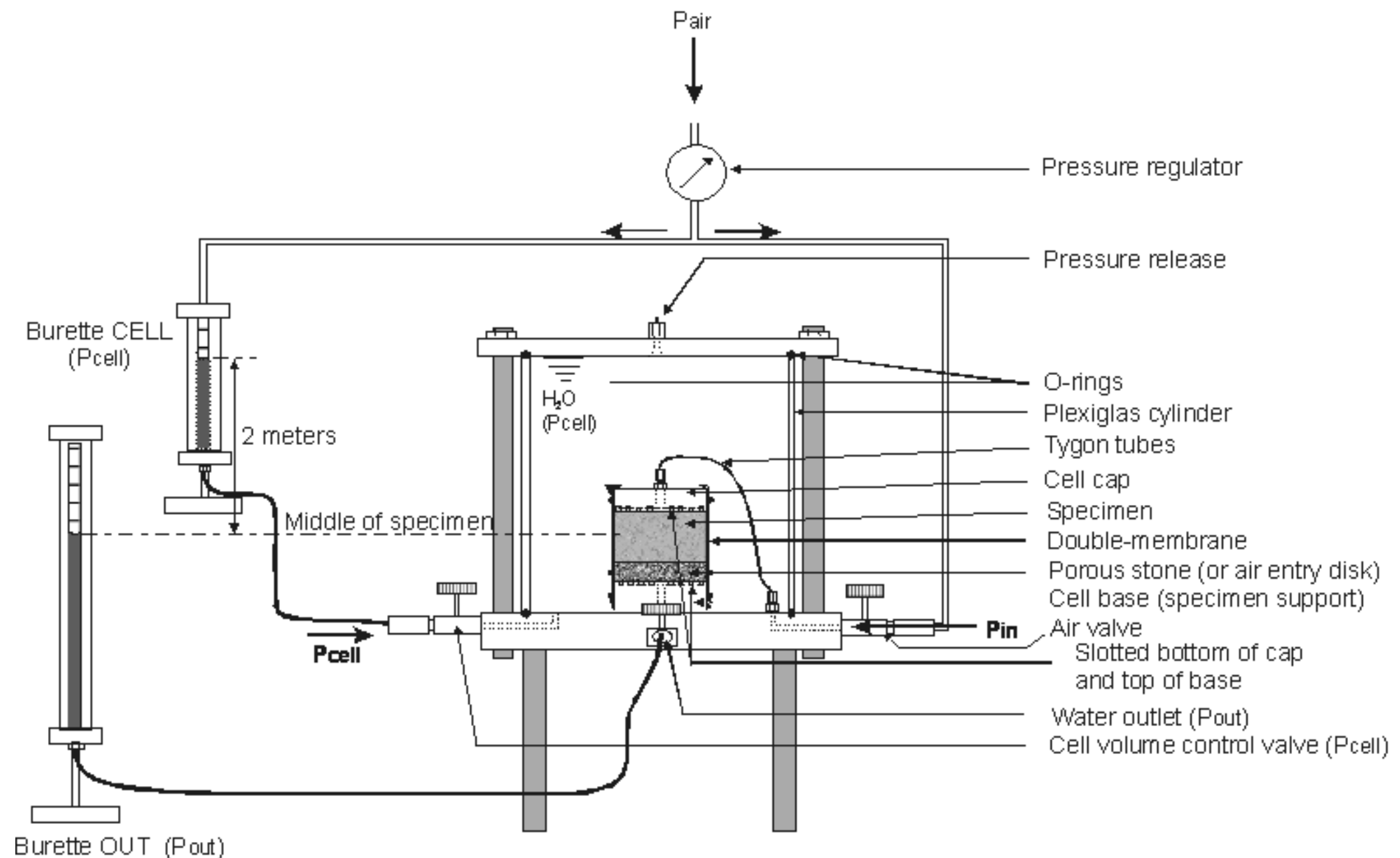

Note: The notation $P$ stands for pressure

Not to scale

Fig. 4. Schematic view of the testing apparatus used to obtain the WRC of DBP 


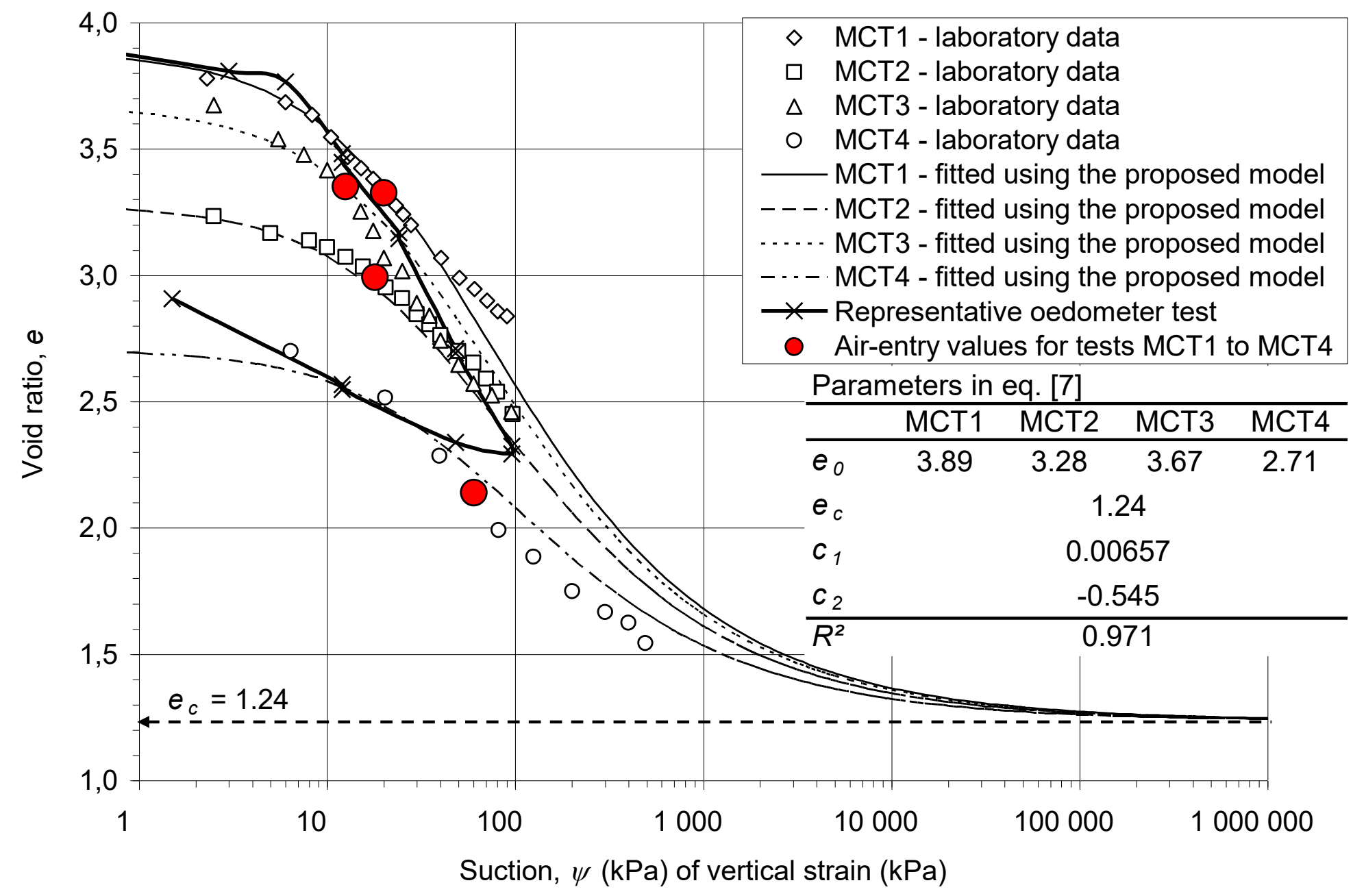

Fig. 5. Suction-induced volumetric changes in DBP 


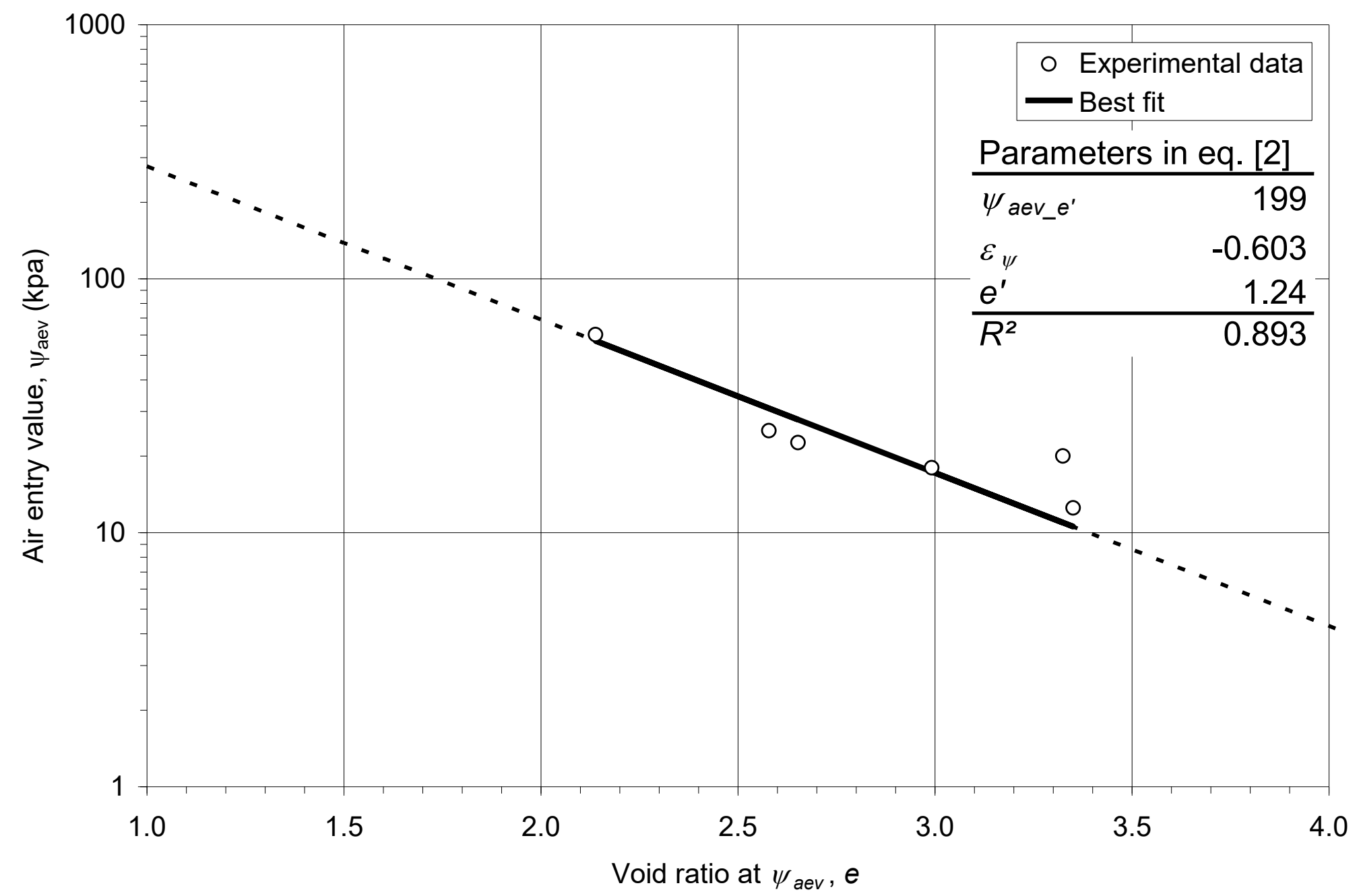

Fig. 6. Air entry value as a function of void ratio for representative tests on DBP 


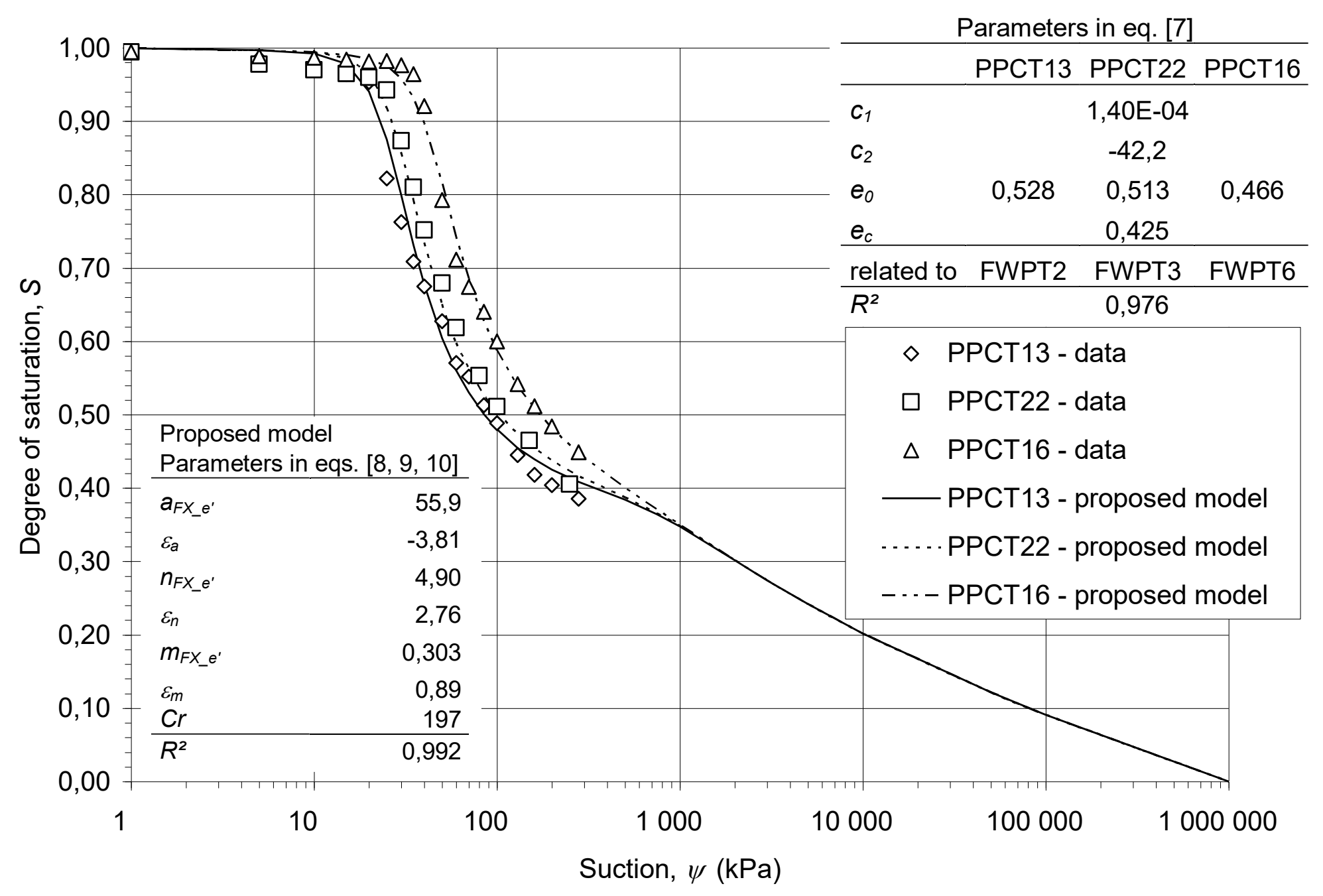

Fig. 7. Proposed WRC model used to represent desaturation of a silty sand. Note: experimental data from Huang (1994) 


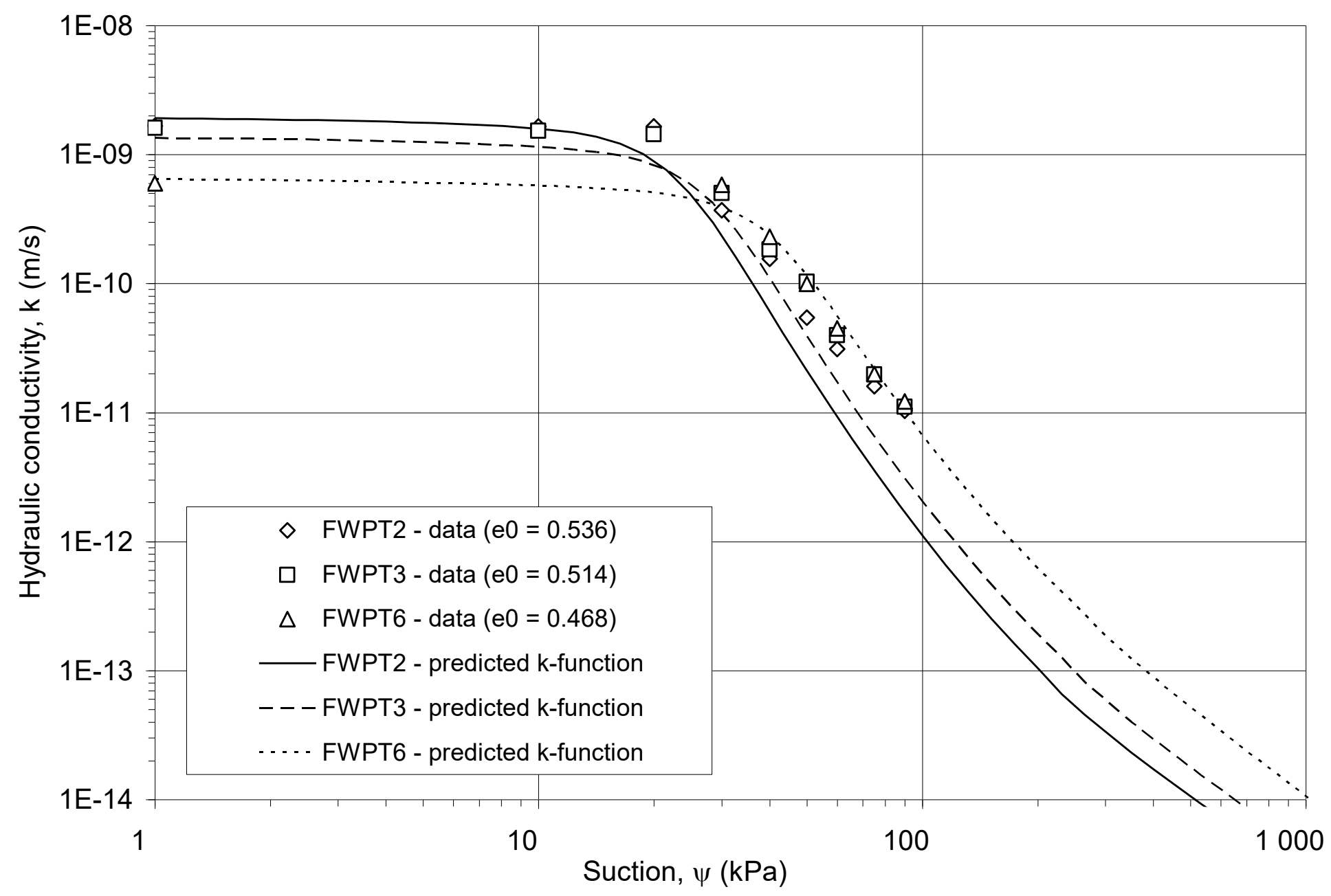

Fig. 8. Hydraulic conductivity function for silty sand reported by Huang et al. (1998) 


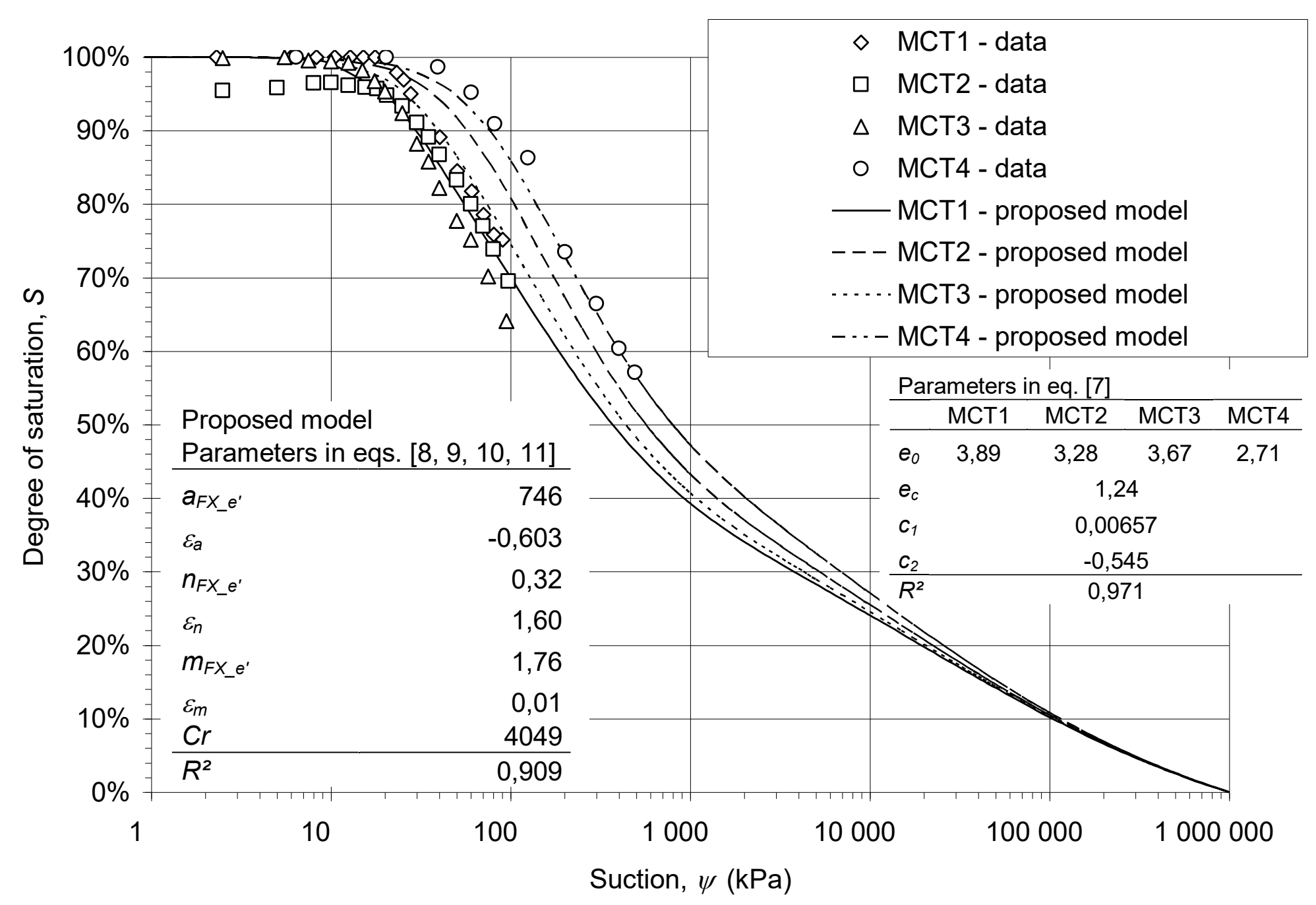

(a) 


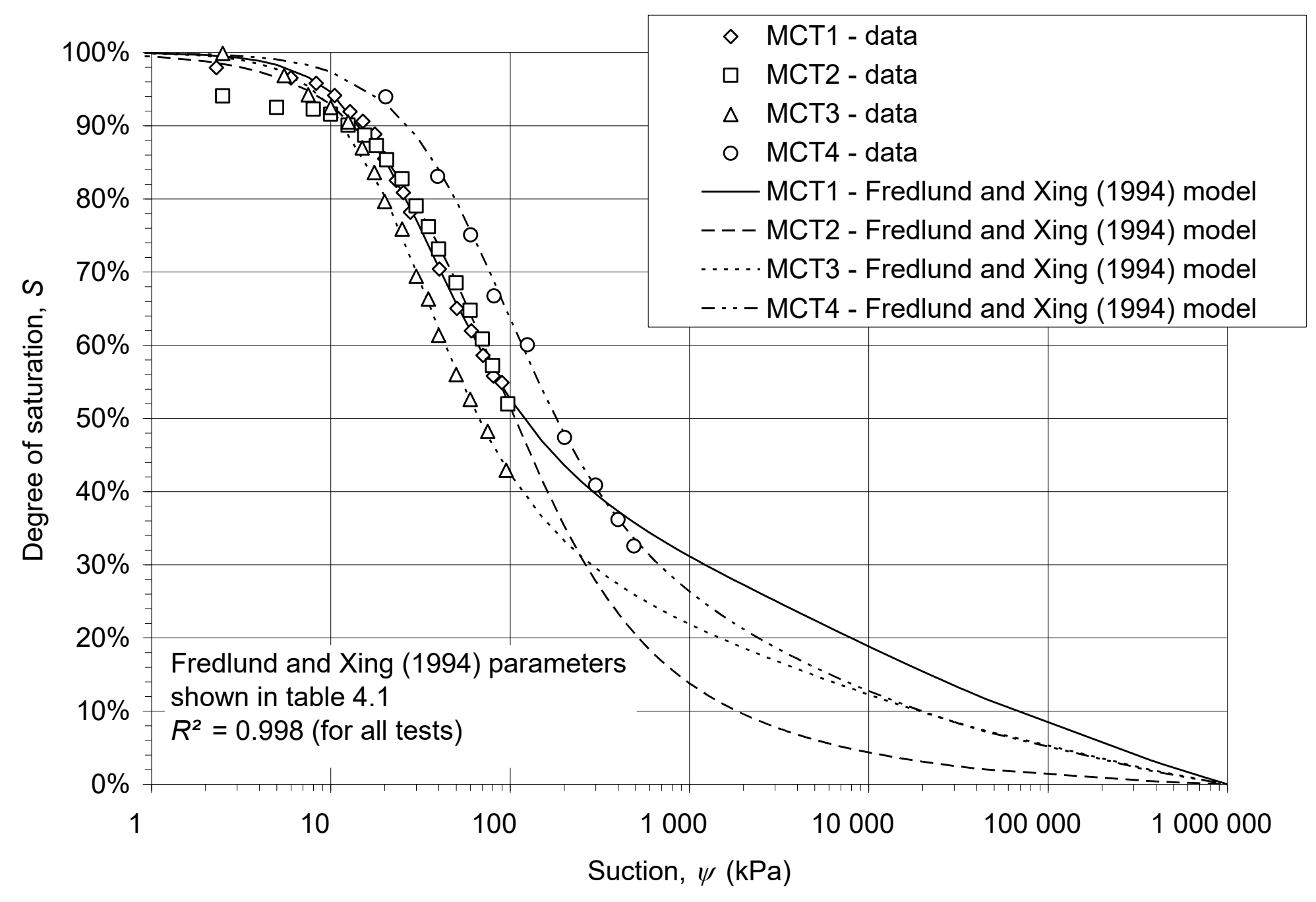

(b)

Fig. 9. Water retention curves for DBP: (a) considering (b) ignoring volumetric changes of shrinkage 


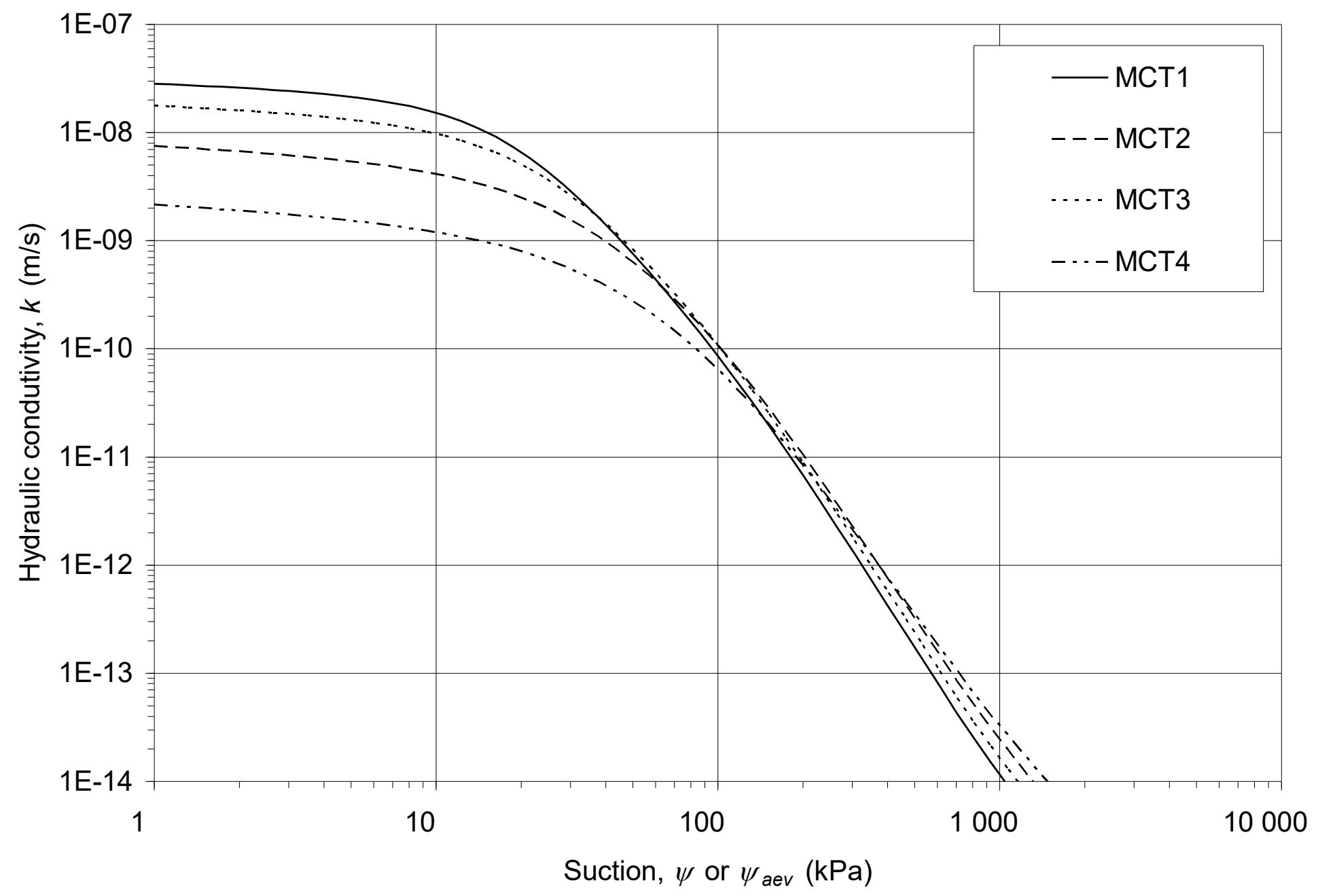

(a) 


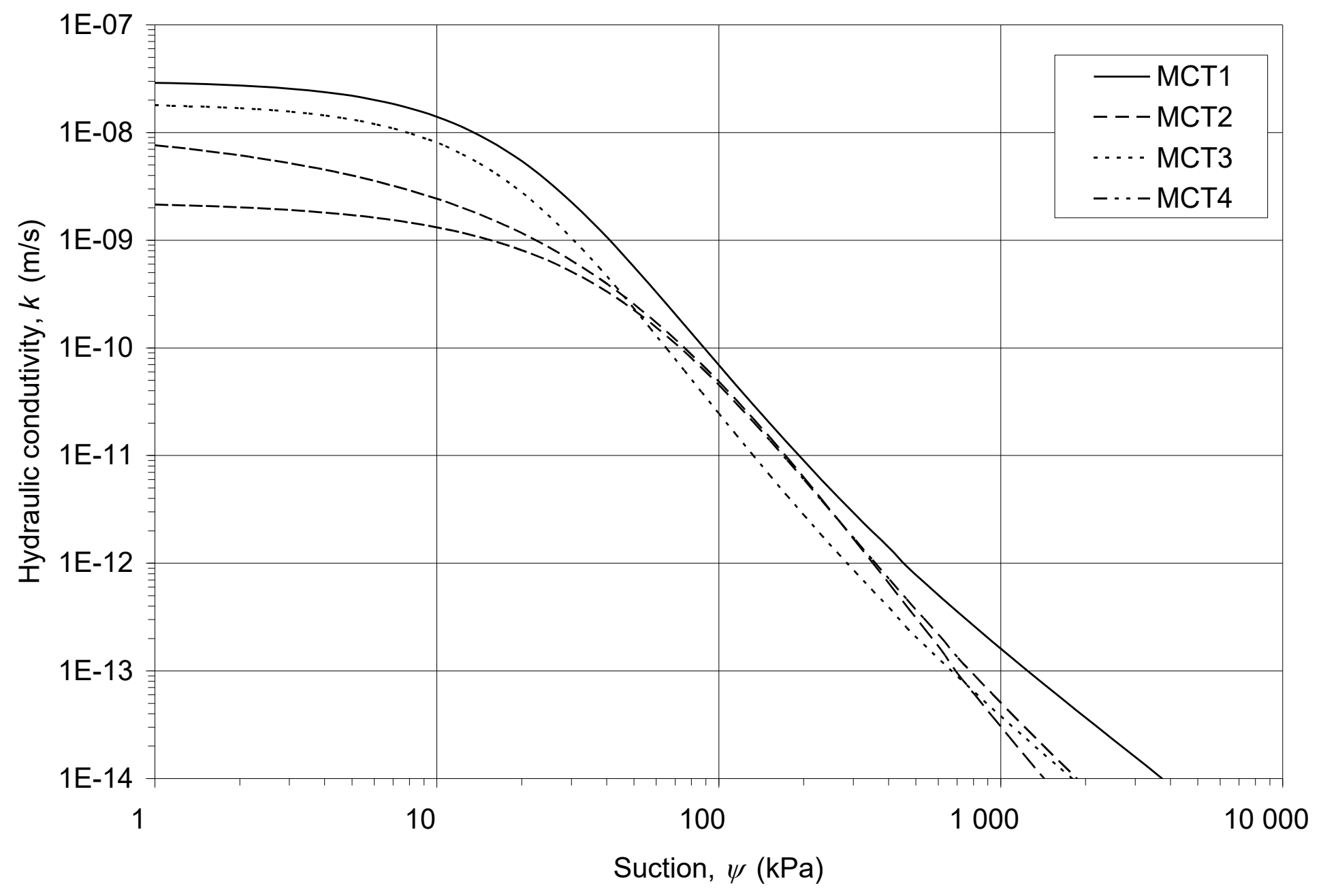

(b)

Fig. 10. Hydraulic conductivity functions for DBP defined from models: (a) considering volumetric changes and (b) neglecting volumetric changes 